\title{
CINCO DIBUJOS DE RAFAEL XIMENO PARA EL LIBRO RETRATO DE LOS ESPAÑOLES ILUSTRES
}

Eduardo BÁEz Macías

Un libro de la Biblioteca Nacional de México que merece reseñarse por su calidad y rareza es el titulado Retratos de los españoles ilustres, con un epitome de sus vidas, impreso en Madrid en 1791 en la Imprenta Real que dirigía don Lázaro Gayguer*. Contiene ciento ocho retratos grabados en metal por artistas de las academias de Bellas Artes de San Fernando de Madrid y de San Carlos de Valencia, acompañados de una breve biografía y siguiendo la costumbre - según dice el prólogo - que tenían los editores de sacar a luz las obras de la literatura nacional, precediéndolas con un retrato del autor, grabado con esmero y buena estampa.

La obra fue planeada para imprimirse por cuadernos (adelantándose a las "entregas" del siglo XIX) que se editaron sucesivamente y se empastaron en un solo volumen de gran tamaño, $28 \times 40 \mathrm{cms}$. El anónimo prologista no aclara a quién se debe la iniciativa para esta empresa, pero sí que fue posible por patrocinio del conde de Floridablanca, ministro de Carlos III y de Carlos IV. Tampoco sabemos con exactitud hasta dónde se pensaba extender esta galería de personajes, pues si en verdad se quería perpetuar la memoria de todos los españoles ilustres, hubieran sido necesarios muchos más pliegos y grabados. Lo que si sabemos por el erudito Antonio Palau y Dulcet ${ }^{1}$ es que el proyecto quedó detenido a la caída de Floridablanca, cuando aún no estaba terminado, pero que gracias a Don Antonio Capmany se concluyó, con las últimas trece biografías que se agregaron a las ya concluidas bajo el valimiento del ministro. Creo que definitivamente debió terminarse o interrumpirse en los últimos años de la centuria, porque el retrato marcado con el número 96 corresponde a don Antonio de Ulloa, fallecido en 1795.

La obra sirvió, desde los más altos niveles políticos, para exaltar la historia de España, resaltando a sus grandes figuras; porque en los estados, como entre los hombres, vivir de glorias pasadas es un refugio, cuando se van agotando las energías vitales del presente. Editaban las vidas de sus "héroes" al mismo tiempo que ponían como programa las esculturas de

\footnotetext{
*Agradezco la colabor ación de Jorge Guerra R. y Judith Puente León. Al primero por poner en mis manos el libro; a la segunda por las fotografias que tomó para reproducir los retratos.

${ }^{1}$ Antonio Palau y Dulcet, Manual del librero hispanoamericano, 2a. Ed., Barcelona, Librería Palau, 1951, tomo V, p. 76, num. 80306.
} 
sus reyes, desde los visigodos, en el Palacio Real que entonces se terminaba. Era un presentimiento de decadencia y la aceptación de que la hegemonía política estaba desplazada irremisiblemente al otro lado de los Pirineos.

Los retratos están encuadernados con un explicable desorden, pues se iban imprimiendo tan pronto se terminaban; y se terminaban en cuanto se disponía de un dibujo o pintura que sirviera de modelo. En consecuencia, no podemos esperar gran veracidad de los personajes y hemos de aceptar que en muchos casos la invención completa fue inevitable; el caso de Rodrigo Díaz de Vivar, por ejemplo. Ya desde la impresión del prólogo se incluía una cláusula que invitaba al público para que todos aquellos que tuvieran algún retrato o dibujo de personaje ilustre lo franquearan a los grabadores para su copiado. De unos pocos se encontrarían excelentes retratos; de otros más pinturas de mediocre factura, y de otros - como ya se dijo- habría que partir de nada, si no es de simples "retratos hablados".

Los retratos en general son de muy buena calidad en cuanto al burilado, pero diferentes en cuanto al dibujo, resultado de la intervención de varios maestros. La mayor parte fueron ejecutados por José Maea y Antonio Carnicero; pero hay cuatro de singular mérito que se copiaron de maestros ya consagrados. Estos son el de Antonio de Leyva, capitán de las guerras de Italia, tomado de uno de Leonardo; ${ }^{2}$ el del duque de Alba, tomado de Ticiano; el de fray José de Sigüenza, copiado del cuadro que Sánchez Coello pintó al cronista escurialense, y el de Guzmán el Bueno, tomado de Van Dick.

Para ilustrar esta reseña reproduzco diez retratos, escogiendo aquellos que tienen relación -o que casi la tuvieron- con las Bellas Artes en México: cinco que dibujó Rafael Ximeno, antes de venir a México para encargarse de la dirección de Pintura en la flamante Academia de San Carlos de la Nueva España; tres que abrió el grabador Fernando Selma y dos de personajes (Bernardo de Balbuena y Juan de Palafox y Mendoza) que han sido parte de la Historia de México.

A partir de las obras ya clásicas de Justino Fenández ${ }^{3}$ y Diego Angulo Iñiguez ${ }^{4}$ la persona y la obra de Rafael Ximeno y Planes van siendo mejor conocidas. De su labor en México tenemos una revisión, puesta al día y

\footnotetext{
${ }^{2}$ Es el que reproduce la Enciclopedia Espasa Calpe.

${ }^{3}$ Justino Fernández, El Arte del Siglo XIX en México, México, Instituto de Investigaciones Estéticas de la UNAM, 1984, 3a. Ed.

${ }^{4}$ Diego Angulo Íñiguez, La Academia de Bellas Artes de México y sus pinturas españolas, Universidad de Sevilla, 1935.
} 
escrita con análisis crítico por Xavier Moyssén. ${ }^{5}$ De su actividad en la Península, anterior a su ingreso en la Historia de México, tenemos otro cuidadoso y reciente estudio de Adela Espinós Díaz y M. Concepción García Saiz. ${ }^{6}$ Estas jóvenes historiadoras citan, entre otras obras, los retratos dibujados por Ximeno para el libro de los españoles ilustres que aquí reseño, y por tratarse de un libro raro y por haberme encontrado con el ejemplar que existe en el fondo antiguo de la Biblioteca Nacional, he considerado de utilidad hacer la reproducción de los dibujos.

Ximeno dibujó los cinco siguientes retratos: Bernardino de Rebolledo, Antonio de Solís, Francisco de Quevedo, Lope de Vega y Calderón de la Barca. El mejor es el último, que posteriomente se encargó de abrir Mariano Brandi. Parece tomado del retrato que guardaba la cofradía de los Presbíteros naturales de Madrid y que debía ser bastante fiel. Pero Ximeno lo mejoró, dotándolo de un gesto severo que en la envolvente obscuridad recuerda los espacios sombrios que se advierten en algunos dramas calderonianos. Pensemos que fue ejecutado cuando aún no se apagaban los fuegos encendidos por la polémica que sostuvieron los defensores del teatro español castizo y los preceptistas clásico-afrancesados, con Clavijo Fajardo a la cabeza, que anatematizaron a Calderón como escritor maldito y corruptor de la escena española. Polémica que se resolvió por entonces y por el favor real del lado de los segundos, al prohibirse los autos sacramentales en la real cédula de 11 de junio de 1765. Pero el hecho de que hubieran incluido su retrato en esta galería de hombres ilustres, en los años mismos en que aún se rompían lanzas de una y otra parte, acredita que el dramaturgo madrileño nunca salió de la vena auténtica y popular del teatro español. El de Lope es otro retrato elocuentemente ambientado. La pluma que rasguea sobre el papel, el brazo izquierdo que se levanta ex-

\footnotetext{
5 Xavier Moyssén E., "La Pintura y el dibujo académico", En Historia del Arte Mexicano, México, Salvat Mexicana de Ediciones, S.A. 1982, fasciculos 65 y 66.

Además de las obras citadas por Moyssén, tenemos noticias de otras que realizó o que, en algún caso, se le atribuyeron, pero que actualmente están perdidas. Son éstas: un San José y un boceto para la Adoración de los Pastores que pertenecieron a Miguel Mata y Reyes; una Virgen del Carmen $(100 \times 75 \mathrm{cms}$.) y un Calvario $(95 \times 60 \mathrm{cms}$.) remitidos en 1884 a la Exposición Universal de Nueva Orleans; una alegoría de América y España, que grabó en cobre Manuel Araoz y que se encontraba en 1887 en la galería de grabado; un boceto para la decoración del ábside de la capilla del señor de santa Teresa, que su viuda vendió a Bernardo Couto. Vid. Eduardo Báez M, Guía del archivo de la Antigua Academia de San Carlos. 1867-1907 (en preparación).

${ }^{6}$ Adela Espinós Díaz, y M. Concepción Saiz, "Algunas obras de Rafael Ximeno y Planes antes de su llegada a México", Separata de Archivo Español de Arte, tomo LI, núm. 202, año 1978, pp. 115-135, Consejo Superior de Investigaciones Cientificas, Instituto Diego Velázquez, Madrid, 1979.
} 
presivamente y la musa clásica del fondo, se conjuntan para manifestar la fecundidad de su genio.

El libro contiene también tres retratos de otro Ximeno: José Antonio Ximeno y Carrera (1757- después de 1807) a veces confundido con Rafael por ser igualmente valenciano y su contemporáneo. ${ }^{7}$ Posible es que entrambos hubiera algún parentesco, pero el conde de la Viñaza, que es la autoridad en la materia, no lo menciona. ${ }^{8}$ De todas maneras sería razonable pẹnsar en una dinastía de pintores Ximeno en ambos lados del mar. En México sabemos que Rafael tuvo un hijo, Mariano, y un nieto, Ángel, que aprendieron en la Academia de San Carlos el oficio de pintor, aunque nunca alcanzaron la notoriedad del progenitor.

De Fernando Selma reproduzco 3 retratos, dibujados por otras manos pero "abiertos" o grabados por él. Este fecundo artista, mejor grabador que dibujante, que había trabajado en obras de grandes vuelos como en las ilustraciones al Quijote impreso en 1780 por la Real Academia Española ${ }^{10}$ participó en el concurso para ocupar la plaza de director de grabado en la Academia de San Carlos de Nueva España, resultó aprobado y recomendado para ocuparla, pero no llegó a embarcar por razones que des-

\footnotetext{
${ }^{7}$ Son los del duque de Alba, Gonzalo Hernández de Córdoba y Antonio Pérez.

${ }^{8}$ Conde de la Viñaza, Adiciones al Diccionario Histórico de los más ilustres profesores de las Bellas Artes en España de D. Juan Agustín Ceán Bermúdez. Compuestas por..., Madrid, Tipografia de los Huérfanos, 1889.

9 Rafael Ximeno casó con doña Luisa Flores Mendizábal Su hijo Mariano era corrector en la Academia en 1845, pero por desaveniencias habidas con la junta directiva renunció a su cargo y no vuelve a haber noticias suyas hasta su muerte ocurrida en Guanajuato en 1855, según declaración de su hijo Ángel, quien también había abrazado el estudio de la pintura en la Academia de San Carlos. También practicó la litografía, porque en 1839 se asoció con la empresa Litográfica de Rocha y Fournier (Vid. Manuel Toussaint. La Litografía en México, México, 1934, p. XVII). Ángel, hijo del anterior, aparece disfrutando una pensión de cuatro reales diarios en la clase de pintura en 1855, un premio en 1856 en la clase de la Estampa, otro premio en 1857 en la clase de Yeso, otro premio en la clase de Copias de cuadros por la que realizó de un toro en 1858, y otro más en 1860 por la copia de un San Juan Niño (¿el de Ingres?). Aquí cesan también las noticias de este Ximeno. Todavía en 1870 se registró en la clase de Grabado - en la ya entonces Escuela Nacional de Bellas Artes - un alumno de nombre Manuel Ximeno, probablemente hijo de Ángel, que vendría a representar una cuarta generación; pero no encuentro más noticias de este, al parecer, último Ximeno. La mala suerte parece que se cebó en la dinastía; desde la muer te de Rafael ocurrida en 1825 , la viuda reclamó una pensión de $\$ 500.00$ anuales a cuenta de los 5881 pesos que la Junta de Gobierno debía a su esposo por concepto de sueldos, pero después de litigar durante 4 años apenas consiguió que le señalaran 25 mensuales. Ángel, el nieto de Rafael, al solicitar una pensión en la Academia en 1855, hacia hicapié en su carencia de recursos económicos. Vid. Eduardo Báez, Guía del Archivo de la Antigua Academia de San Carlos, 1844-1867, México, Instituto de Investigaciones Estéticas de la UNAM, 1976, Passim.

${ }^{10}$ Fernando Calvo Serraller, en prefacio a Ilustraciones al Quijote de la Academia por varios dibujantes y grabadores, en la imprenta de Joaquín Ibarra. Madrid, I780, Ediciones Turner, 1978.
} 
conocemos. ${ }^{11}$ Suyos son los grabados de Saavedra Faxardo, el culto autor de las Empresas Políticas; el de Juan de Rivera, realizado con verdadero preciosismo, que muestra al virrey-arzobispo de Valencia exhibiendo el plano arquitectónico para el seminario de Corpus Christi fundado por él; el de Hugo de Moncada, capitán en las guerras de Italia, el del cardenal Cisneros, el de Cervantes y los dos mejores que son el de Alonso de Ercilla, en quien encarnan los ideales de las letras y las armas, y el del marqués de Santillana, el poeta de las vaqueras y las serranillas, ataviado con gran apego a su época.

Los dos retratos que finalmente publico corresponden a dos personajes que dejaron huella en la historia y la cultura colonial: Juan de Palafox y Mendoza y Bernardo de Balbuena. ${ }^{12} \mathrm{El}$ del obispo angelopolitano fue dibujado por José Maea y grabado por Mariano Brandi, pero cualesquiera que hayan sido sus modelos se aparta de la iconografía tradicional, abundante por cierto, que sobre Palafox se conserva en México. El de Bernardo de Balbuena, bardo de la ciudad de México, fue dibujado y grabado por Rafael Esteve. Los otros noventa y ocho retratos que hacen el grueso del libro constituyen la galería de personajes ilustres, o cuando menos importantes para la historia de España, y es de estimarse que los editores no se hayan limitado a los validos y políticos que nunca escapan a la vanidad de hacerse retratar en libros, sino que en una misma tesitura dieran cabida al soldado y al escritor, al poeta y al marino, al matemático y al religioso. La España de la ilustración no podía menos que reconocer el genio y el esfuerzo, cualesquiera que fuesen los campos en que se manifestaban. Los personajes retratados evocan girones de las glorias de España: hombres del temple de Sebastián Elcano, Cortés y Hernando de Soto; eruditos como Vives, Ambrosio de Morales, Feijó y el Brocense; los maestros de capilla como Espinel, inventor de la "espinela", y Francisco de Salinas, inmortalizado en la suavísima oda de Fray Luis de León. Todos ellos siempre intercalados entre pintores, poetas y arquitectos. Se incluyen también religiosos y algunos místicos como Juan de Ávila, Jerónimo Gracián fray Luis de Granada y el maestro León, aunque no a San Juan de la Cruz porque para entonces ya estaba canonizado y a sus santos, como a sus reyes, las reservaban galerías aparte.

Para la ejecución de los retratos intervinieron, además de los artistas que ya cité expresamente, dibujantes y grabadores de las academias de

${ }^{11}$ D. Angulo I, op. cit, pp. 34-35.

12 No se reproduce el de Hernán Cortés, dibujado por Carnicero y grabado por J A. Carmona, porque ya fue muy bien estudiado por Manuel Romero de Terreros en Los Retratos de Hernán Cortés, México, Ántigua Librería de Robredo de José Porrúa e Hijos. 1944. 
Madrid y Valencia, algunos famosos y algunos casi desconocidos. Entre los dibujantes, junto a maestros que ostentaban un prestigio ya bien ganado como Antonio Carnicero, José Camarón, López Enguídanos, Esteve y José Maea que hizo la mayor parte de los retratos, aparecen los nombres de otros dibujantes poco conocidos. En cuanto a los grabadores, al lado de Manuel y Antonio Salvador Carmona, que habían mantenido viva la tradición del grabado en España, se encuentra una larga lista de nombres que, presumiblemente y para esa época, eran alumnos aventajados a quienes se quiso estimular contratándolos para abrir las láminas. ${ }^{13}$

${ }^{13}$ Los otros dibujantes fueron: Manuel Eraso, José del Castillo, Manuel de la Cruz, J. Ferro, José Beraton, Salesa y J.R. Rodriguez. Los grabadores: Bartolomé Vázquez, Alegre, Noseret, Barcelón, Gamborino, Navia, Muntaner, Brieva, Ballester, Martí, Boix, Garcia Sanz, Besanzón, Albuerne, Brunete, Esquivel, Mariani y Ametller. 

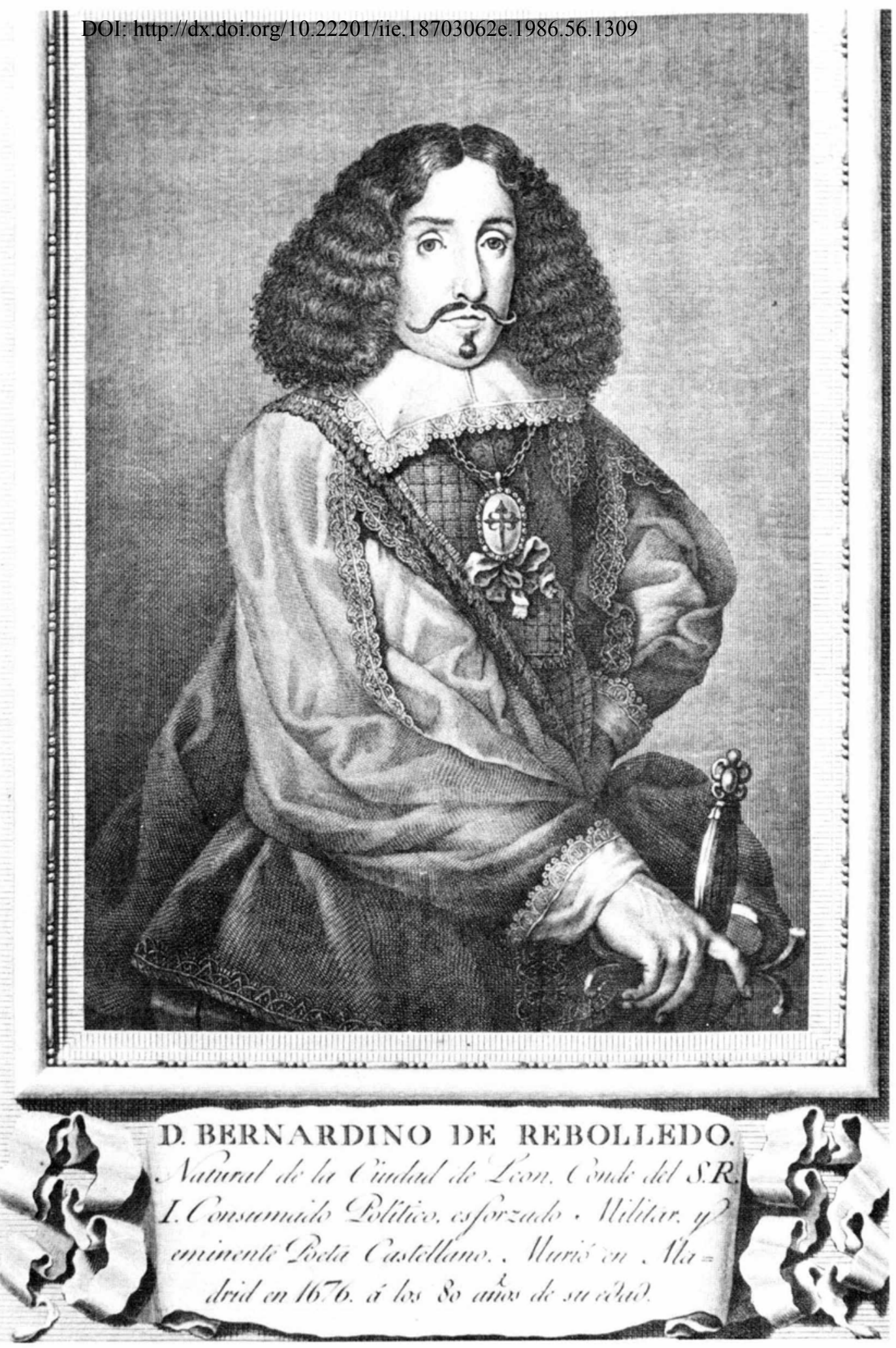

Figura 1. Bernardino de Rebolledo. Rafael Ximeno dibujó, J. Ballester grabó. 


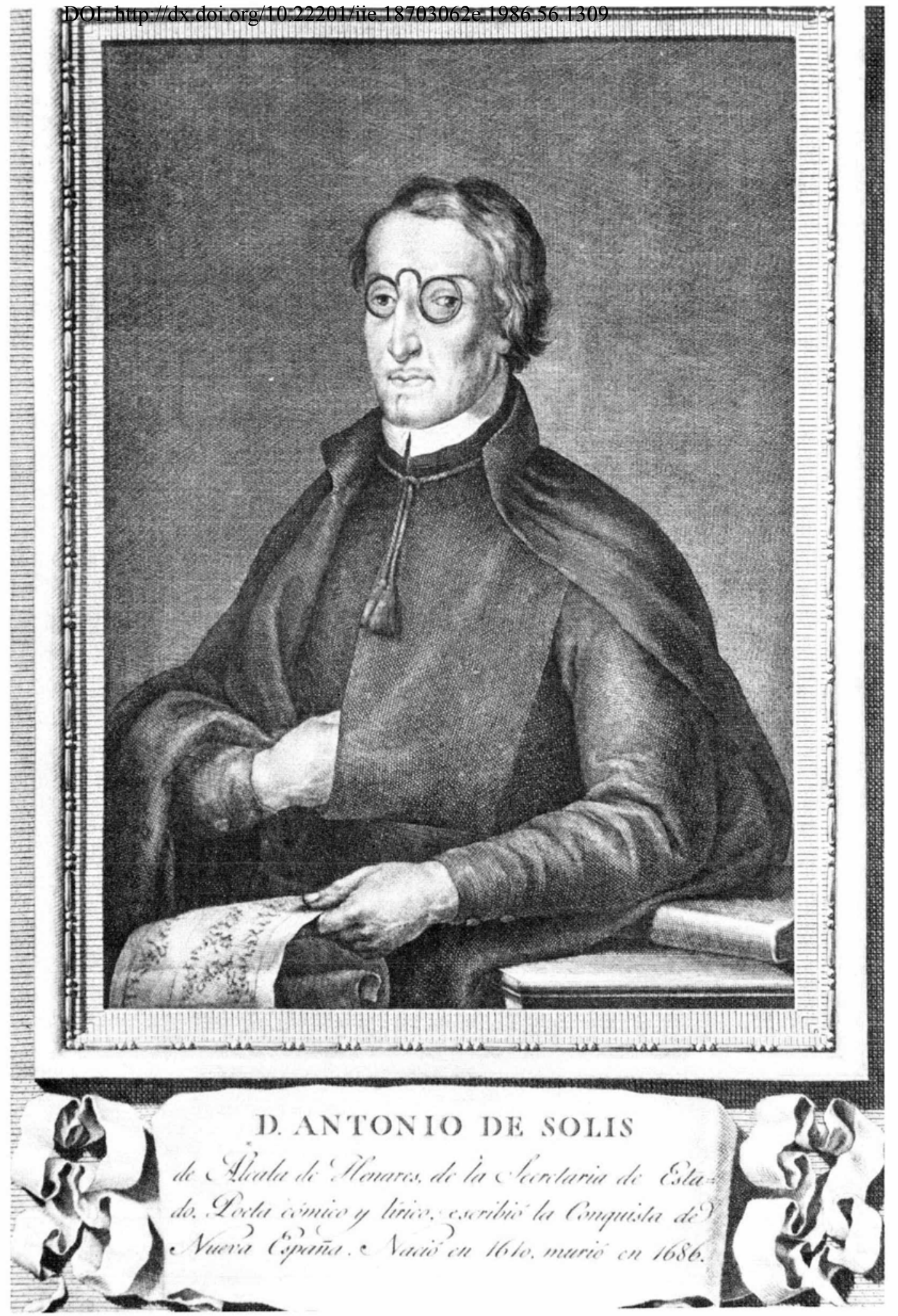

Figura 2. Antonio de Solís. Rafael Ximeno dibujó, J. A. Carmona grabó. 

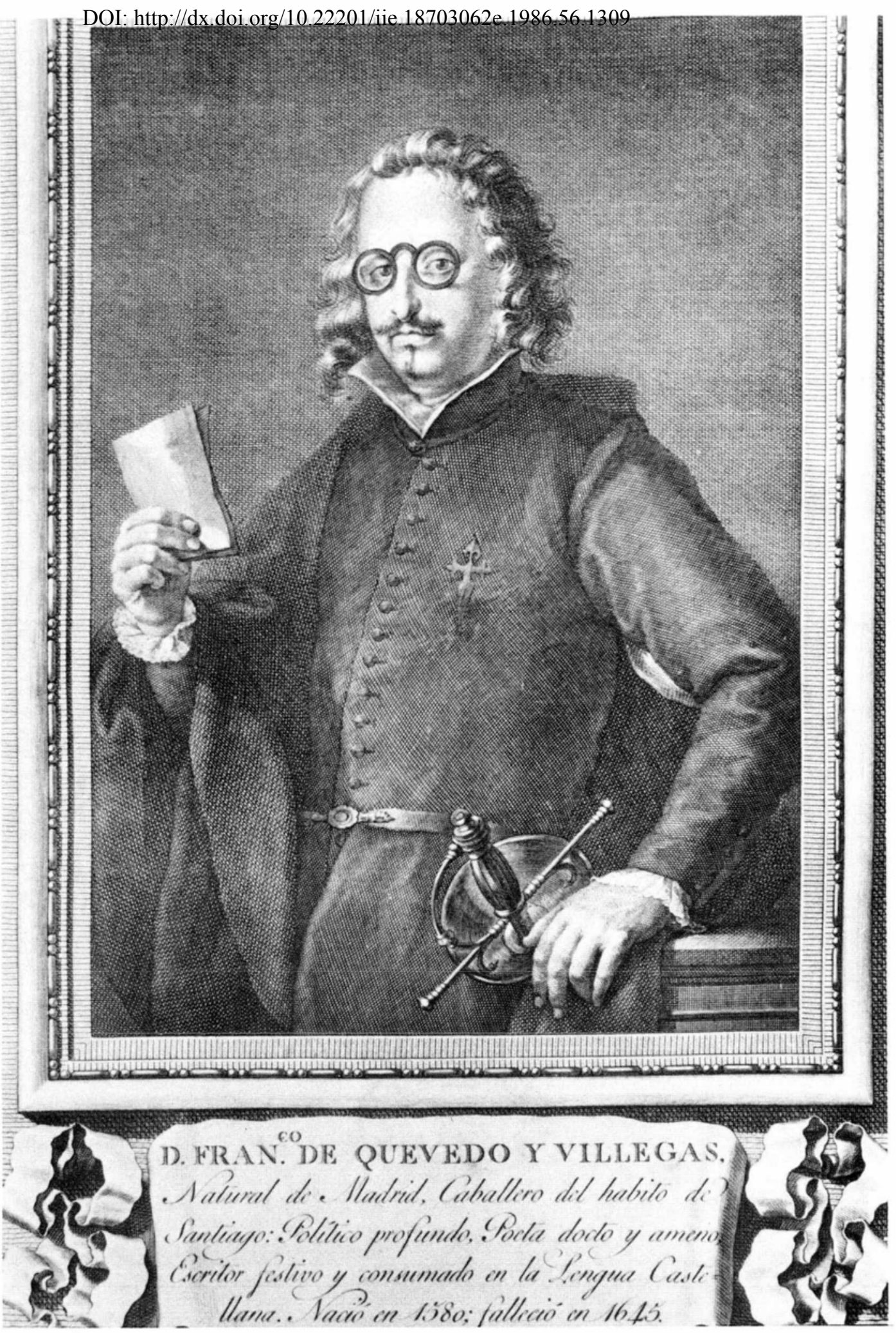

Figura 3. Francisco de Quevedo y Villegas. Rafael Ximeno dibujó, M. Brandi grabó. 

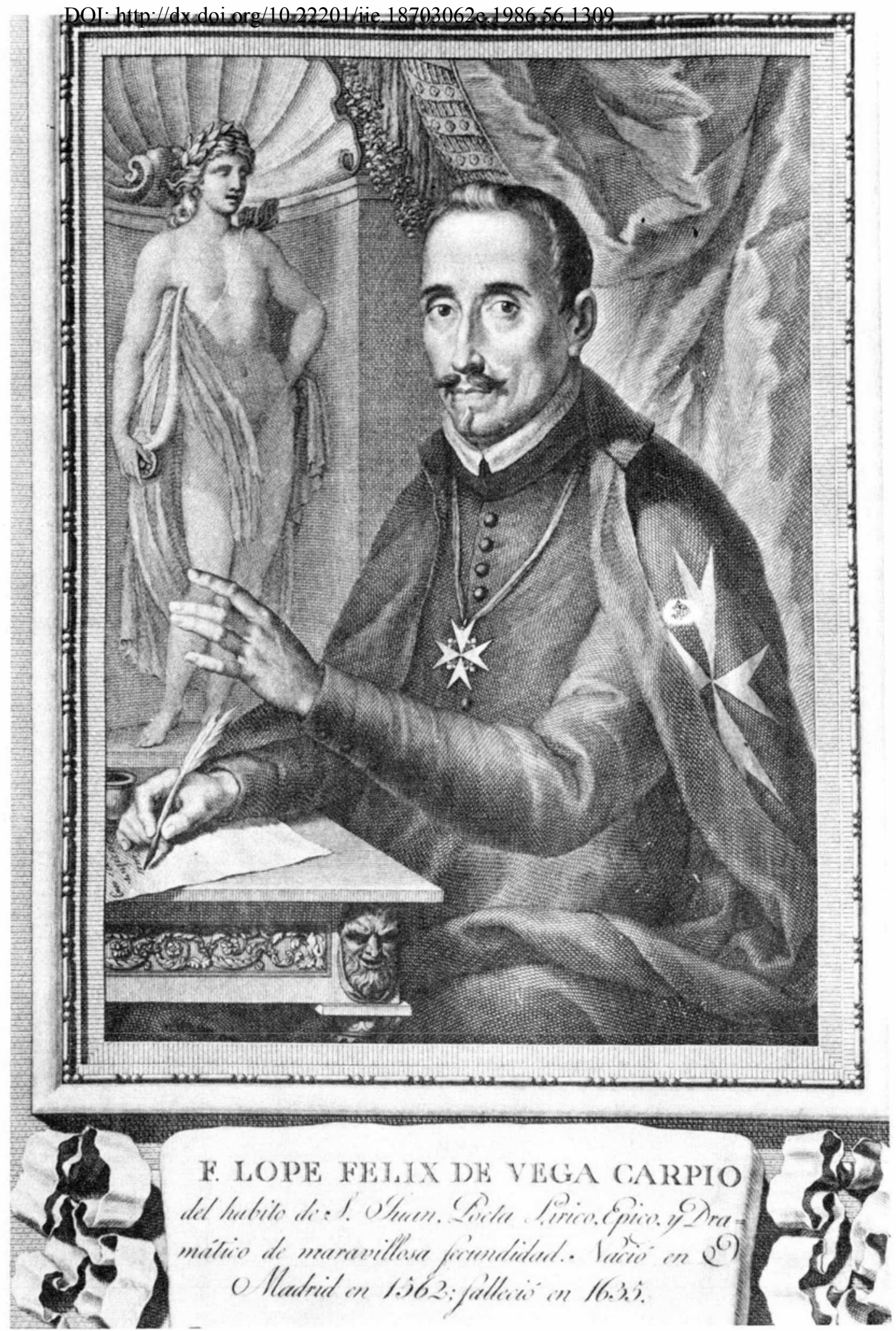

Figura 4. Félix Lope de Vega y Carpio. Rafael Ximeno dibujó, Fernando Selma grabó. 
DOI: http://dx.doi.org/10.22201/iie.18703062e.1986.56.1309
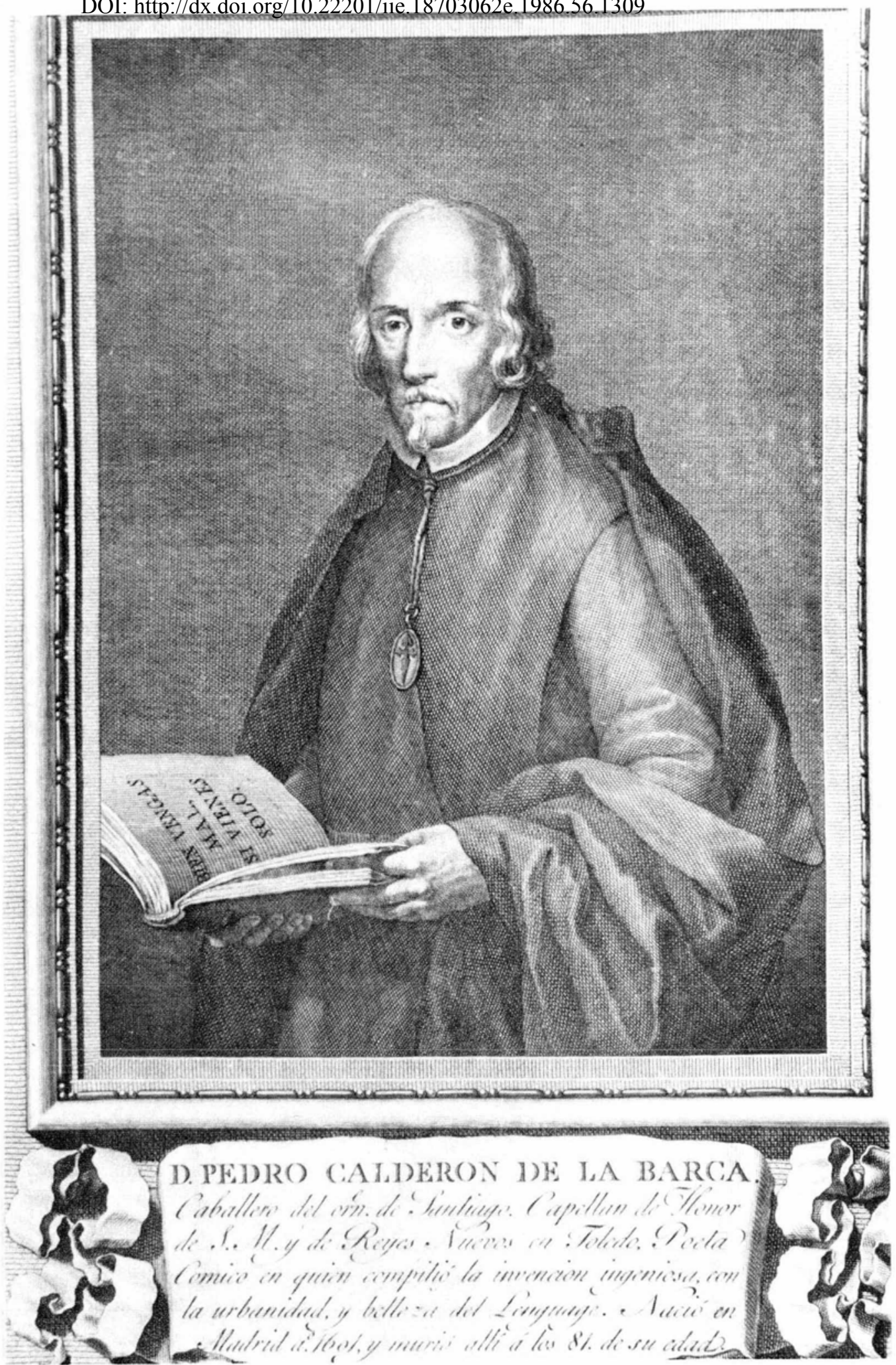

Figura 5. Pedro Calderón de la Barca. Rafael Ximeno dibujó, M. Brandi grabó. 

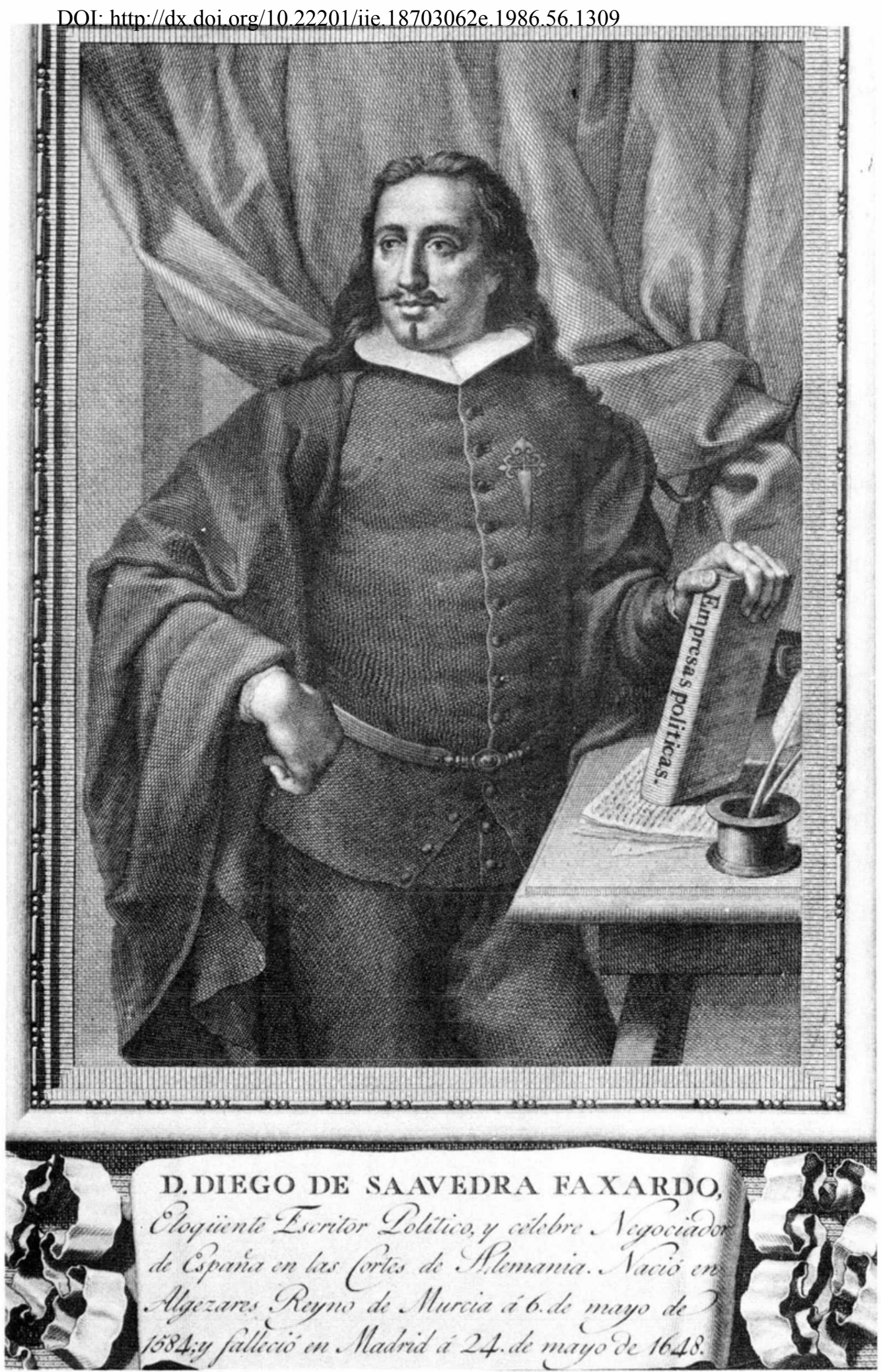

Figura 6. Diego de Saavedra Faxardo. F. Ramos dibujó, F. Selma grabó. 

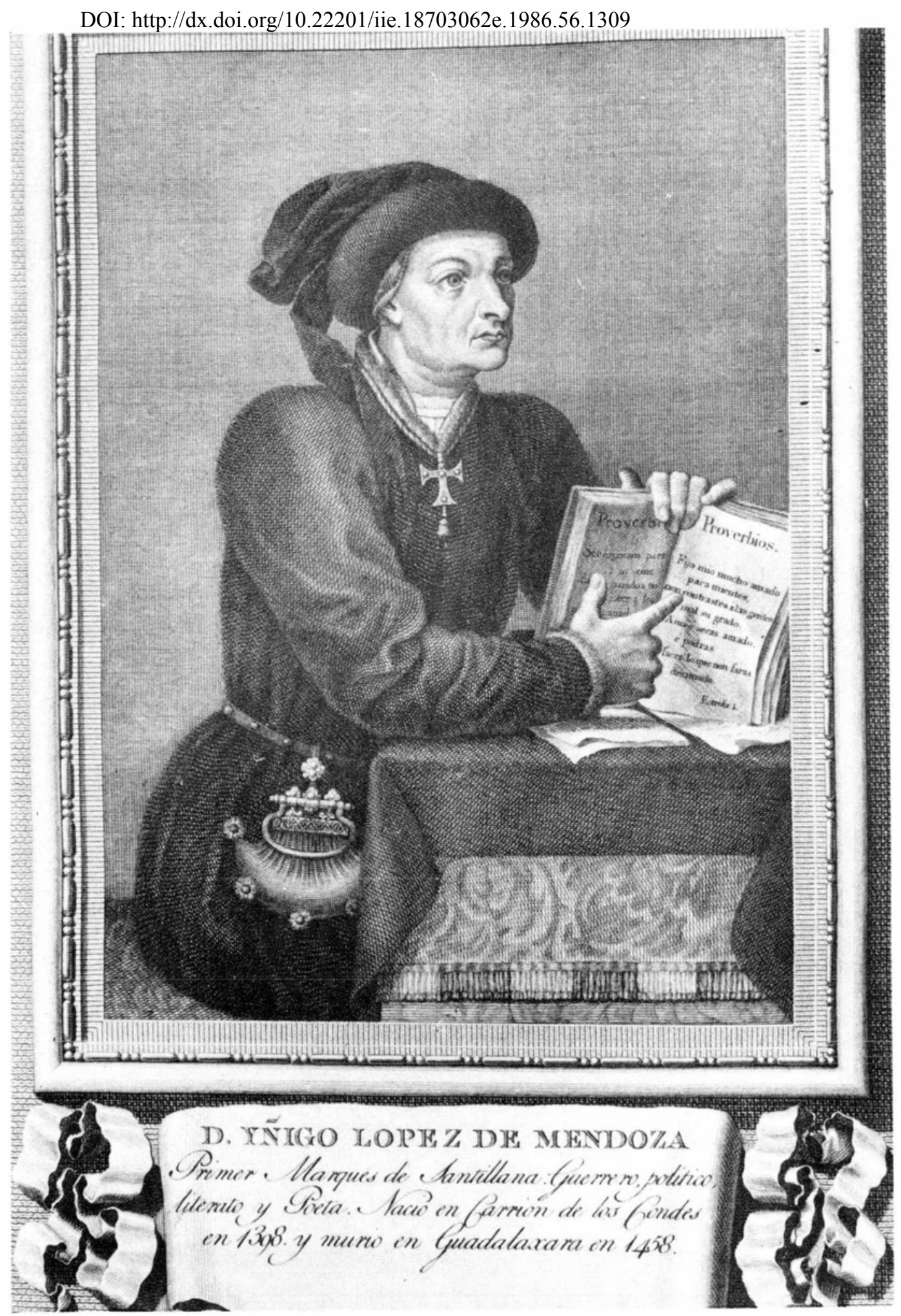

Figura 7. Ínigo López de Mendoza, primer marquéz de Santillana. Josef Maea dibujó, F. Selma grabó. 

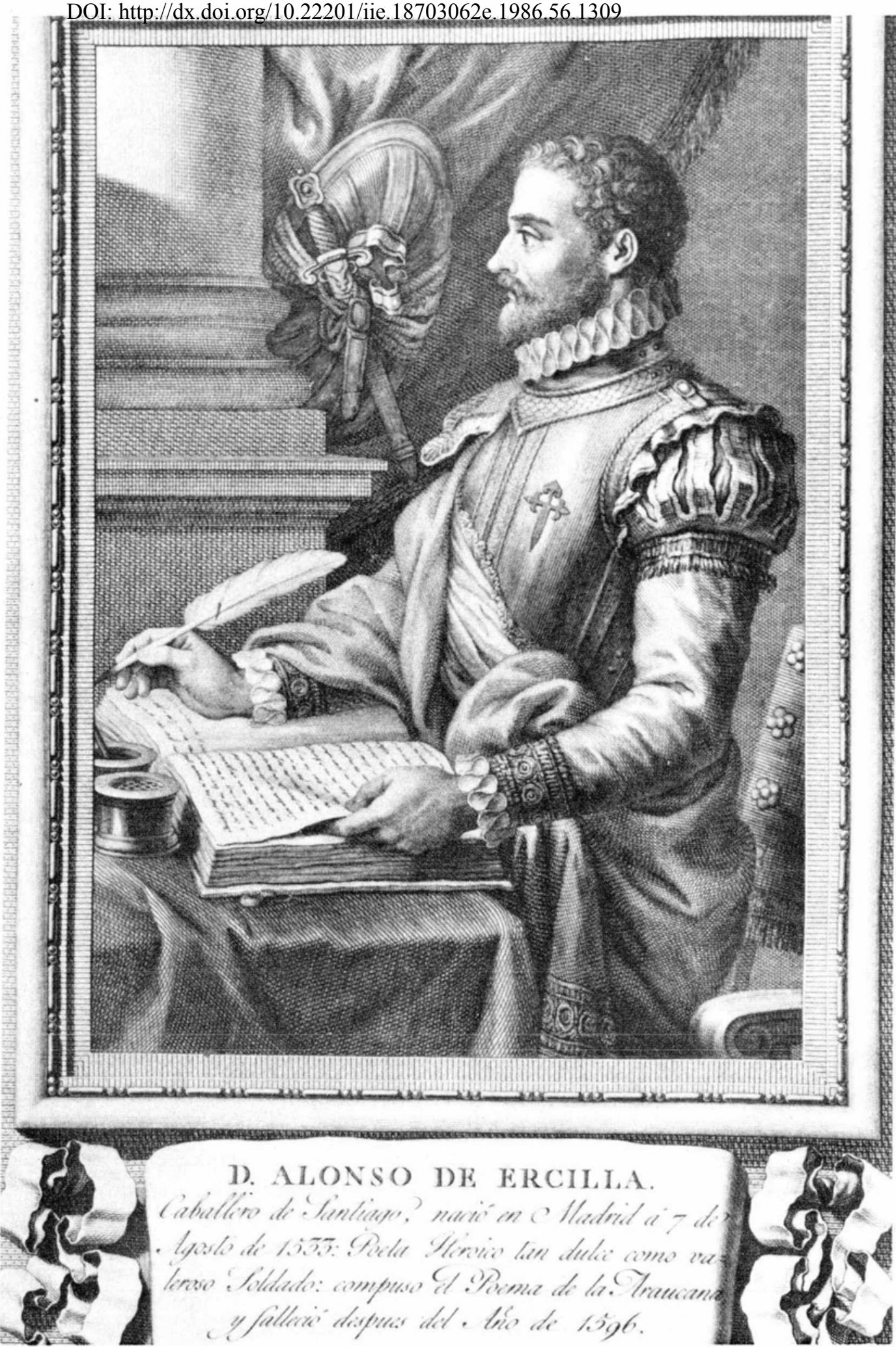

Figura 8. Alonso de Ercilla. A. Carnicero dibujó, F. Selma grabó. 
DOI: http://dx.doi.org/10.22201/iie.18703062e.1986.56.1309
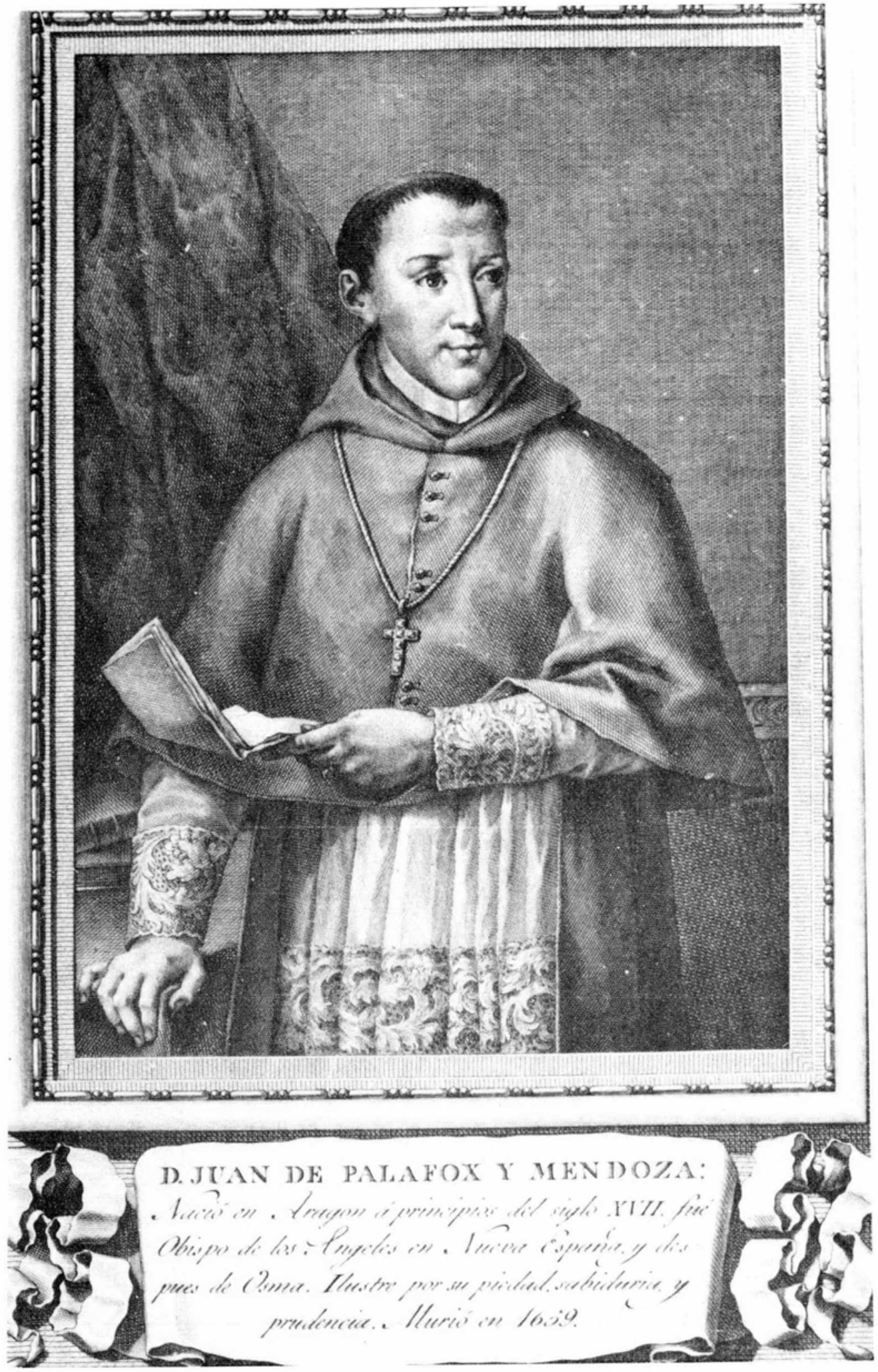

Figura 9. Juan de Palafox y Mendoza. Josef Maea dibujó, M. Brandi grabó. 
DOI: http://dx.doi.org/10.22201/iie.18703062e.1986.56.1309
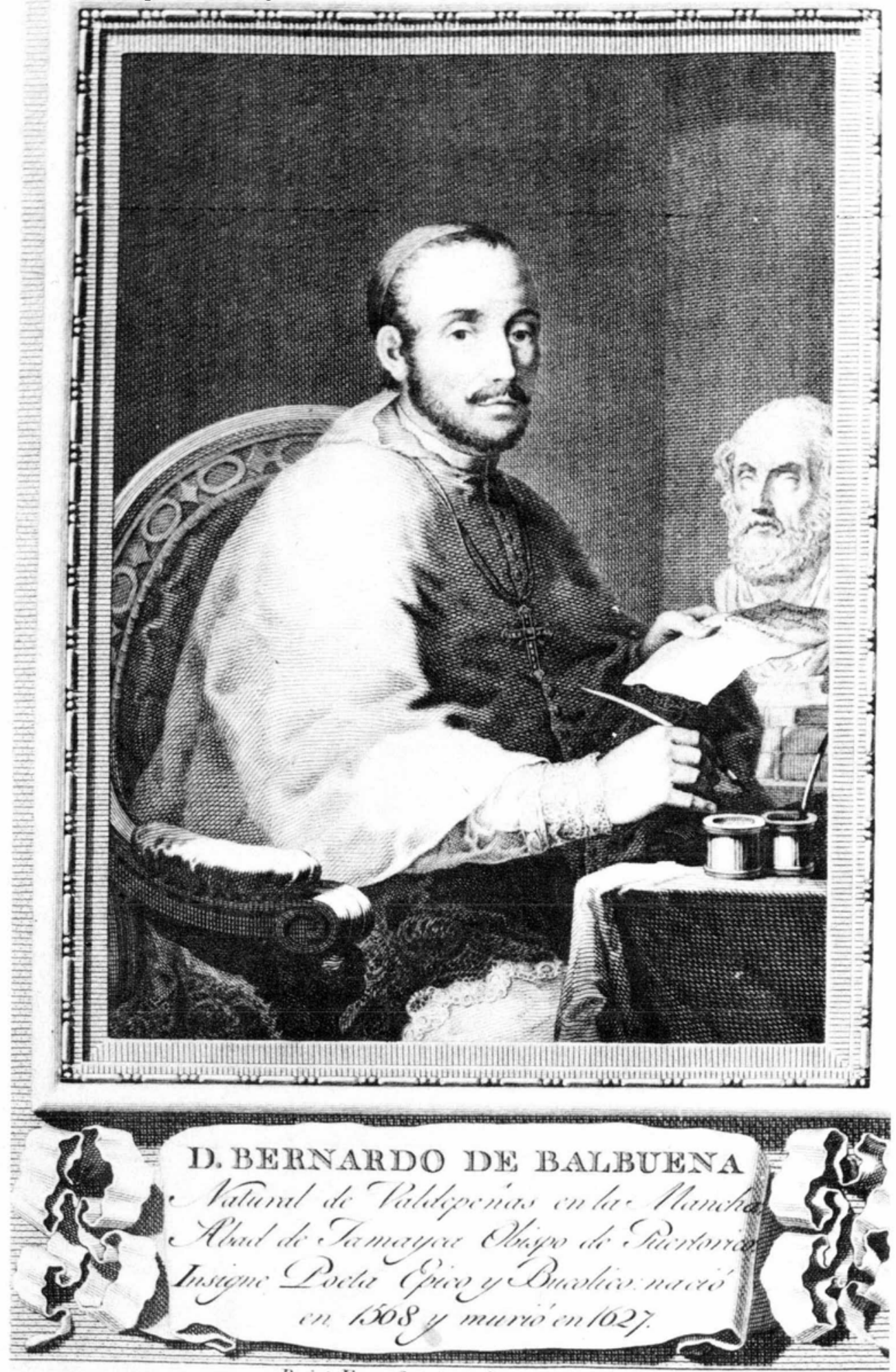

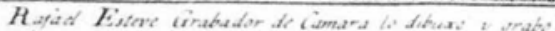

Figura IU. Bernarao ae baıbuena. Dıbujó y grabó Rafael Esteve. 